\title{
Cholangitis as a late complication of choledochoduodenostomy: the sump syndrome
}

An 84-year-old woman was admitted for cholangitis. Her leukocyte count was $14.76 \mathrm{Gpt} / \mathrm{L}$ (normal range $4.0-$ $10.0 \mathrm{Gpt} / \mathrm{L}$ ), total bilirubin was $67 \mathrm{mmol}$ (normal $<17 \mathrm{mmol}$ ), alkaline phosphatase was $6.48 \mathrm{mmol}$ (normal range $0.58-1.74 \mathrm{mmol}$ ) and $\gamma$-glutamyltransferase was 7.04 (normal range $0.1-0.7$ ). The past medical history was remarkable for a cholecystectomy and a choledochoduodenostomy carried out 21 and 15 years ago, respectively. An abdominal ultrasound carried out after admission to the referring hospital showed dilation of the common bile duct (CBD) and choledocholithiasis. Therapy with tazobactam/piperacillin and metronidazole was started. Endoscopic retrograde cholangiopancreatography (ERCP) was carried out twice at the same hospital but failed both times, and the patient was referred to our medical center.

We carried out another ERCP, which disclosed an opening in the duodenal bulb ( $\bullet$ Fig. 1) and an intact ampulla of Vater. Cholangiography revealed multiple filling defects in the distal CBD and contrast extravasation into the stomach via the duodenal orifice (choledochoduodenostomy) ( $\bullet$ Fig. 2). Deep cannulation of the intrahepatic bile ducts was accomplished after passing a guide wire ( $\bullet$ Fig. 2 ). The intrahepatic biliary tree could only be visualized on occlusion cholangiography with the balloon inflated above the choledochoduodenostomy ( $\bullet$ Fig. 3). A sphincterotomy was carried out with subsequent extraction of multiple stones and a large amount of sludge ( Fig. 4). The patient recovered and on follow-up 6 months later, she is doing well.

The "sump syndrome" is rarely seen in the present time. This syndrome is a complication of a choledochoenterostomy and results from the accumulation of debris, which enters into the CBD from the duodenum $[1,2]$. Often, the debris cannot escape distally through the intact ampulla of Vater and starts accumulating within the distal, nonfunctioning CBD, resulting

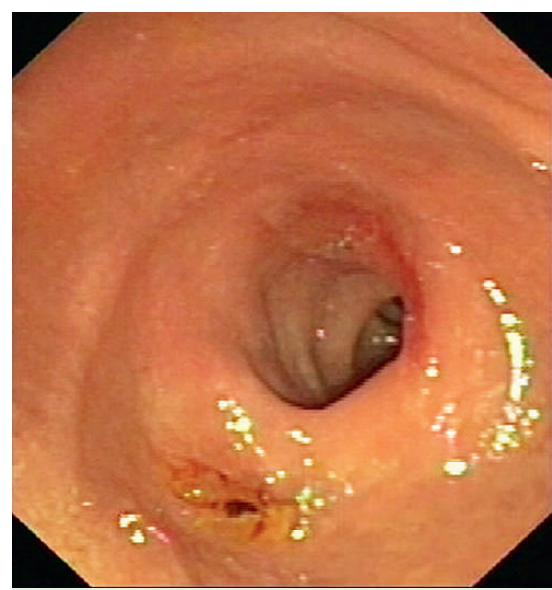

Fig. 1 The opening of the choledochoduodenostomy located at the 7 o'clock position.

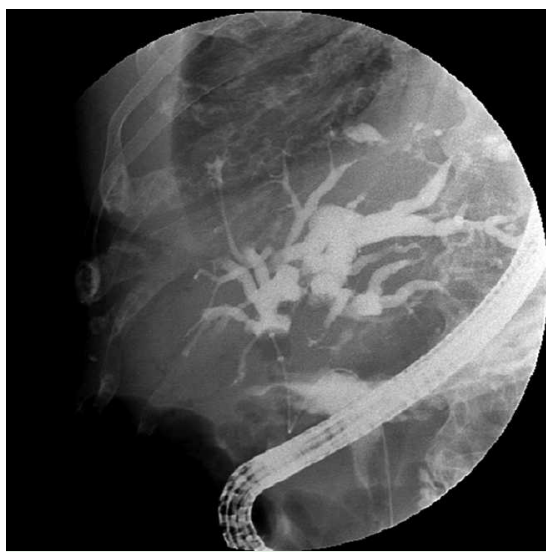

Fig. 3 Occlusion cholangiogram showing the intrahepatic biliary tree. Note the balloon located above the choledochoduodenostomy.

in the creation of a "sump". The debris induces the formation of sludge and stones, which can occlude the entire CBD. Clinically, patients present with recurrent attacks of abdominal pain or cholangitis $[2,3]$. The sump syndrome can be treated surgically by creating a Roux-en-Y hepaticojejunostomy and by endoscopy by performing a biliary sphincterotomy and extracting the debris from the $\operatorname{CBD}[2,3]$.

Endoscopy_UCTN_Code_CCL_1AZ_2AK

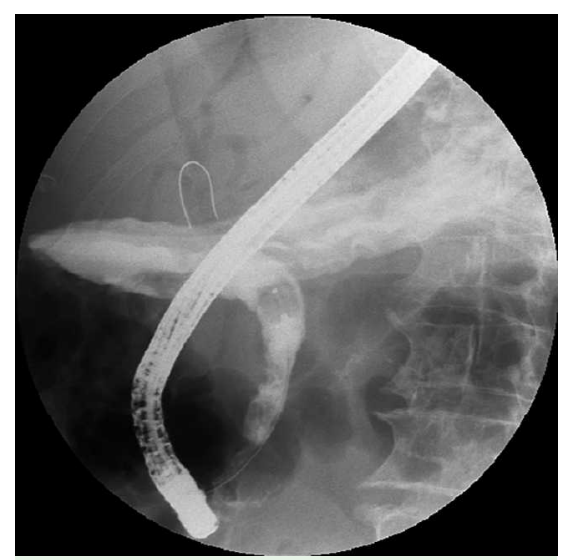

Fig. 2 Cholangiogram showing multiple filling defects in the common bile duct and extravasation of contrast material into the stomach through the choledochoduodenostomy.

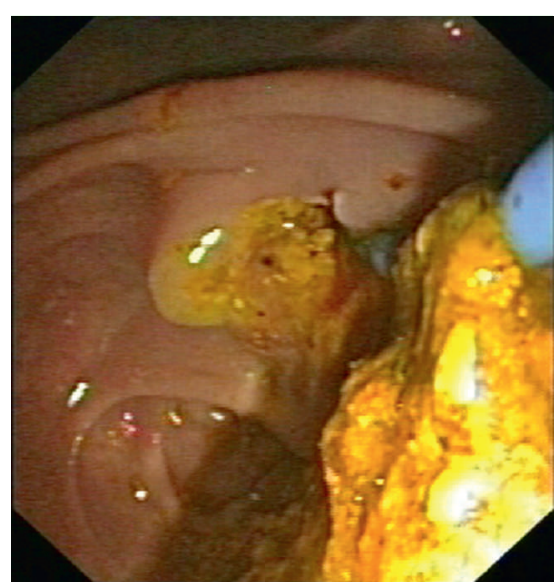

Fig. 4 Sphincterotomy for extraction of the multiple, large stones and biliary sludge.

M. Venerito ${ }^{1}$, L. C. Fry ${ }^{1}$, S. Rickes ${ }^{2}$, P. Malfertheiner ${ }^{1}$, K. Mönkemüller ${ }^{1}$ Division of Gastroenterology, Hepatology and Infectious Diseases, Universitätsklinikum Magdeburg, Ottovon-Guericke University, Magdeburg, Germany

2 St Salvator Krankenhaus, Halberstadt, Germany 
References

1 Miros M, Kerlin P, Strong R et al. Post-choledochoenterostomy "sump-syndrome". Aust N Z J Surg 1990; 60: 109-112

2 Ell C, Boosfeld C, Henrich R et al. Endoscopic treatment of the "sump syndrome" after choledochoduodenostomy: a new technique using an amplatzer septal occluder. Z Gastroenterol 2006; 44: 1231 - 1235

3 Siegel HJ. Duodenoscopic sphincterotomy in the treatment of the "sump syndrome". Dig Dis Sci 1981; 26: $922-928$
Bibliography

DOI $10.1055 / \mathrm{s}-0029-1214660$

Endoscopy 2009; 41: E142-E143

(c) Georg Thieme Verlag KG Stuttgart · New York . ISSN 0013-726X

\section{Corresponding author}

\section{K. Mönkemüller, MD, PhD, FASGE}

Division of Gastroenterology,

Hepatology and Infectious Diseases

Universitätsklinikum Magdeburg

Otto-von-Guericke University

Leipziger Straße 44

39120 Magdeburg

Germany

Fax: +49-391-6713105

klaus.moenkemueller@med.ovgu.de 